\title{
Increased sensitivity of Au-Pd nanolayer on tapered optical fiber sensor for detecting aqueous Ethanol
}

\author{
Ahmad Shukri Muhammad Noor ${ }^{1,2^{*}}$ D, Ali Talahn ${ }^{1}$, Mohd Anwarul Arif Rosli ${ }^{1}$, Punithavathi Thirunavakkarasu ${ }^{3}$ \\ and Nizam Tamchek ${ }^{4}$
}

\begin{abstract}
Background: Optical fiber sensors gains popularity as an alternative and a better solution compared to its electronics counterpart. Especially in detecting hazardous materials, optical fiber sensors prove to have many advantages such as miniaturization, remote yet real-time sensing and immune to electromagnetics interference.

Methods: In this paper, we used a 40um tapered standard multi-mode fiber coated with gold (Au), palladium (Pd) and mixtures of Au-Pd nano-composites to detect hazardous ethanol in its various concentration in aqueous environment. Interrogation were made possible using UV-VIS light source, and changes in absorbance and intensity were recorded via spectrometer.

Results and Conclusion: Ethanol ranging from 20\% till 100\% were investigated. It was found that the composition of nanomaterial coating on the developed sensors strongly affected the sensing performance. From the experiments carried out, the sensor with a gold palladium nanocomposite layer with a 2: 1 ratio of gold to palladium produced the highest sensitivity, which is $0.74 / \mathrm{vol} \%$ concentration of Ethanol. The fabricated fiber sensor also exhibits fast response and recovery time of $13 \mathrm{~s}$ and $6 \mathrm{~s}$ respectively.
\end{abstract}

Keywords: Nanoparticles, Optical sensors, Ethanol concentration, Gold, Palladium

\section{Background}

Recently, optical fiber sensors have been in the limelight since they are being utilized in various fields such as environmental monitoring, medical imaging and diagnostics, forensics, aviation and even in the military [1, 2]. Optical fiber sensors earn this accolade due to their many advantages such as miniaturization, flexibility, fast response and capability for real time and in-situ sensing deployment as well as capability of remote sensing [3, 4]. This increases the desirability of optical fiber sensors as compared to electrical based transducers $[5,6]$, especially when it comes to chemical detection $[7,8]$, humidity $[9,10]$, and also vibration sensing $[11,12]$.

\footnotetext{
* Correspondence: ashukri@upm.edu.my

${ }^{1}$ Wireless and Photonics Network Research Centre of Excellence, Faculty of Engineering, Universiti Putra Malaysia, 43400 UPM Serdang, Selangor, Malaysia ${ }^{2}$ Department of Computer and Communication Systems Engineering, Faculty of Engineering, Universiti Putra Malaysia, 43400 UPM Serdang, Selangor, Malaysia

Full list of author information is available at the end of the article
}

Tapered fiber optic sensors are particularly popular due to their high sensitivity towards their surroundings $[13,14]$. It is not only the enhancement of sensitivity of the tapered fibers sensors that makes them a preferable choice for optical fiber based sensors, their ease of fabrication makes them even more desirable as they are easily reproducible and reliable $[15,16]$. The tapering causes a huge reduction in the size of the core and that leads to penetration of light signal into the cladding which in turn enables the interaction of the light with the surrounding medium which allow the tapered fiber to be employed as a sensor $[17,18]$.

Ethanol is a commonly utilized chemical in various industries such as medical, food processing, beverages and even as a replacement fuel in automotives [19, 20]. Ethanol has a high volatility and flammability that can be dangerous for humans and living organisms, thus making the sensing of Ethanol crucial and important [21]. Mostly, commercial Ethanol sensors available are 

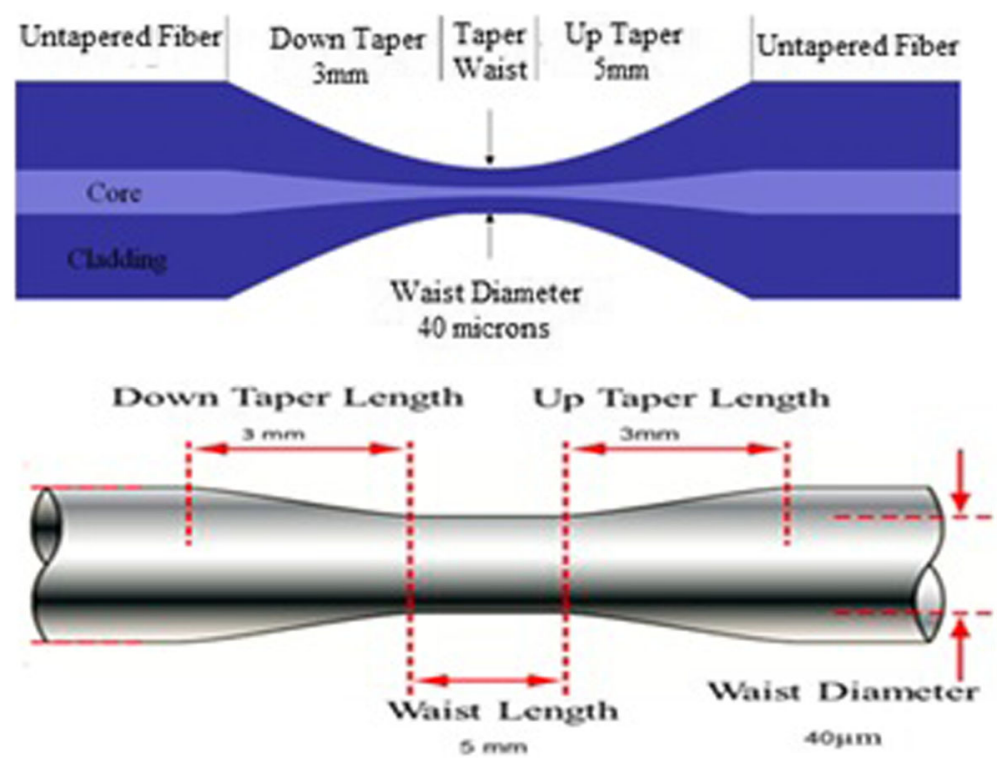

Fig. 1 Illustration of a tapered fiber dimensions

electrical based transducers which rely on resistance and voltage readings for detection [22, 23]. Safety features are required when electrical based sensors are used due to Ethanol's flammability that might cause it to ignite when sparks are formed or heat is transferred. This makes the monitoring of Ethanol concentrations risky because of the fire hazards associated with Ethanol.

Researchers are now looking to optical fiber sensors as an alternative for detecting Ethanol. According to previous research conducted, a fiber optic surface Plasmon resonance (SPR) sensor coated with a layer of gold was used to detect Ethanol in an aqueous solution [24]. This sensing was based on refractive index changes of the solution as the ethanol concentration increased caused changes to the SPR wavelength. Other research include tapered fiber optic tip coated with graphene oxide layer and used as a reflectance based sensor to detect Ethanol concentrations [13]. A sensitivity of $0.0086 / \mathrm{vol} \%$ units of Ethanol in water was obtained. In this paper we propose a tapered multimode fiber optic coated with $\mathrm{Au}$ and $\mathrm{Pd}$ nanocomposite layer in order to obtain a highly sensitive response towards ethanol detection.

Table 1 Sensor configuration

\begin{tabular}{ll}
\hline Sensor & Coating \\
\hline Sensor 1 & $\mathrm{Au}$ \\
Sensor 2 & $\mathrm{Pd}$ \\
Sensor 3 & $\mathrm{Au}: \mathrm{Pd}(2: 0.7)$ \\
Sensor 4 & $\mathrm{Au}: \operatorname{Pd}(2: 1)$ \\
\hline
\end{tabular}

\section{Methods}

A standard multi-mode fibre with core and cladding, diameter of $60.2 \mu \mathrm{m}$ and $124 \mu \mathrm{m}$ respectively, was used to fabricate the tapered fiber optic sensor. The fiber optic was tapered using the Vytran Glass Processing Workstation. The up and down taper transition length was set to $3 \mathrm{~mm}$ and the waist length was set for $5 \mathrm{~mm}$. The waist diameter was set to $40 \mu \mathrm{m}$ as illustrated in the Fig. 1.

All nanomaterials used in this experiment were purchased from (Hangzho Company China). Four configurations of fiber sensors were set up for detect Ethanol as shown in Table 1.

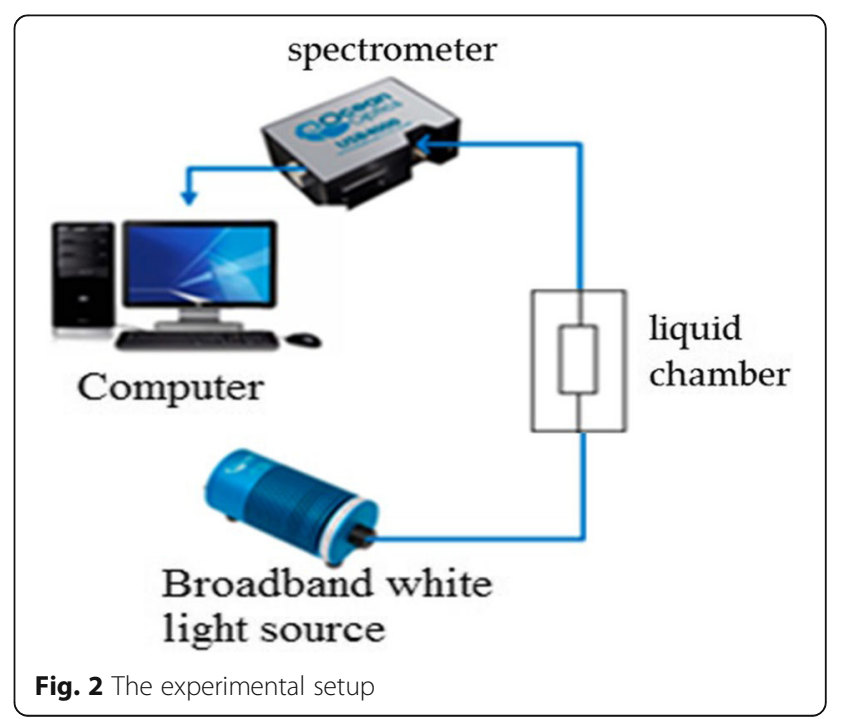


All the nanomaterial layers were deposited on the tapered fiber region using the drop casting technique and following that the sensors were placed in a $70^{\circ} \mathrm{C}$ oven for the annealing process $[13,25]$.

Figure 2 shows the experimental setup for the tapered optical fiber sensor. The input of the sensor is connected to a halogen white light source (HL 2000) from Ocean Optics which has a wavelength range of $360 \mathrm{~nm}$ to
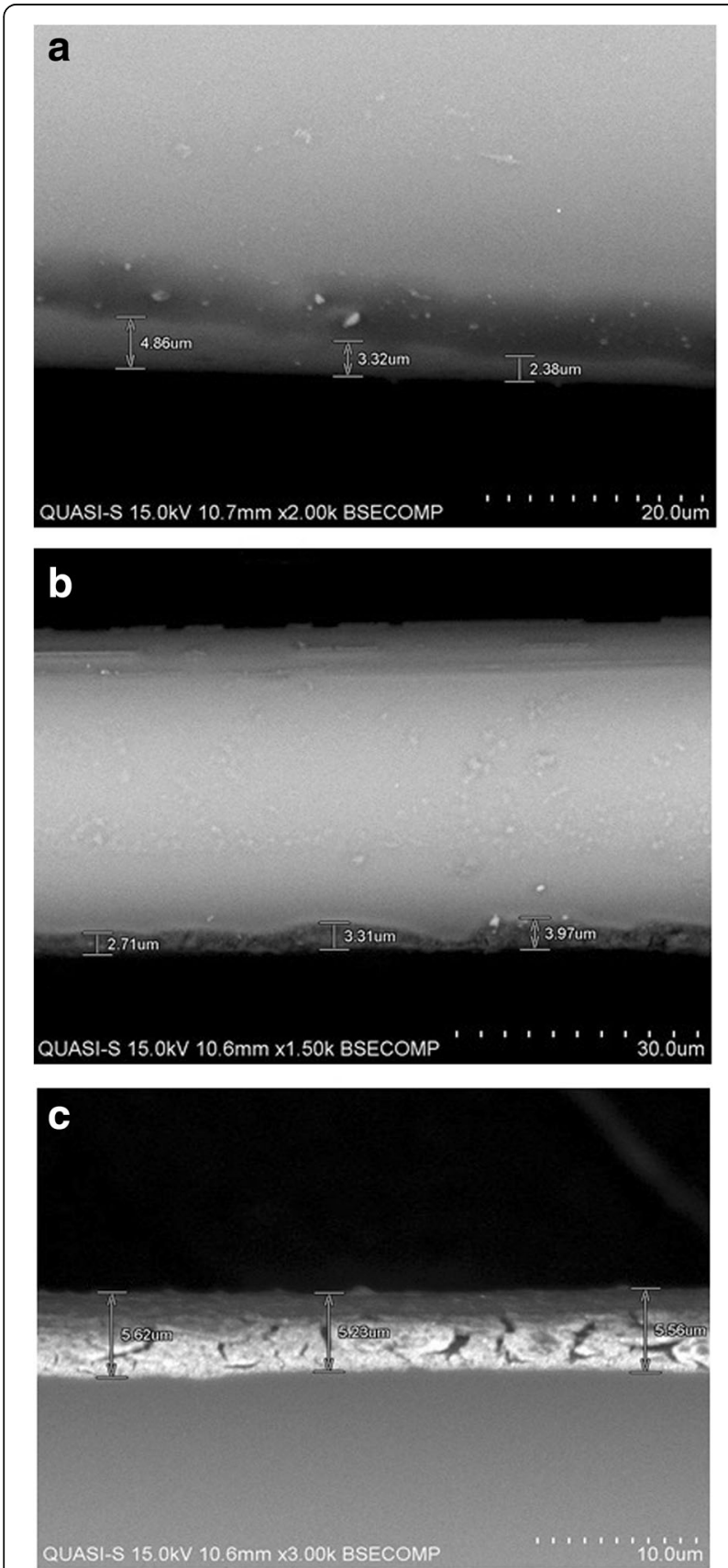

Fig. 3 a SEM image to show the thickness of the gold layer, (b) SEM image to show the thickness of the palladium layer, (c) SEM image to show the thickness of the mixture of gold and palladium
$2400 \mathrm{~nm}$. A spectrometer (USB 4000) from Ocean Optics was then connected to the output of the sensor with a detection range of $360 \mathrm{~nm}$ to $1100 \mathrm{~nm}$. The output from the spectrometer was connected to a computer with spectra suite software for processing. The tapered fiber optic sensor was then immersed in different concentrations of Ethanol starting from $20 \%$ up to $100 \%$.

\section{Results and discussion}

The morphology of the nanocomposite is investigated using scanning electron microscopy (SEM). Figure 3a-c shows the SEM images for the palladium, gold and palladium-gold nanocomposite layer respectively, with a magnification of 50um. In the magnified figure of the sensor shown in Fig. 3a, the gold layer is seen to cover the tapered region with an average thickness of 3.31um. In Fig. 3b, the tapered region has a palladium layer with an average thickness of $2.60 \mathrm{um}$. In Fig. 3c, it can be observed that the nanocomposite layer of palladium and gold has an average thickness is 5.34um. All figures show that the nanomaterial has covered the tapered region of the fiber completely.

Figure 4 shows the SEM image of the gold and palladium nanocomposite layer made a magnification of 10,000 on a glasses substrate to show the morphology of the nanocomposite coating on the substrate. From the SEM image it can be observed that the nanocomposite has coated glass substrate completely with no obvious clumping of the nanomaterials.

The absorbance and intensity spectrums of the gold nanoparticles coated sensor are presented in Fig. 5a and $b$ respectively. All the spectrums in this research were normalized to air. The results show that the absorbance levels increase as the concentration of Ethanol increases. This result is confirmed by the intensity results which show a corresponding decrease as the Ethanol concentration increases.

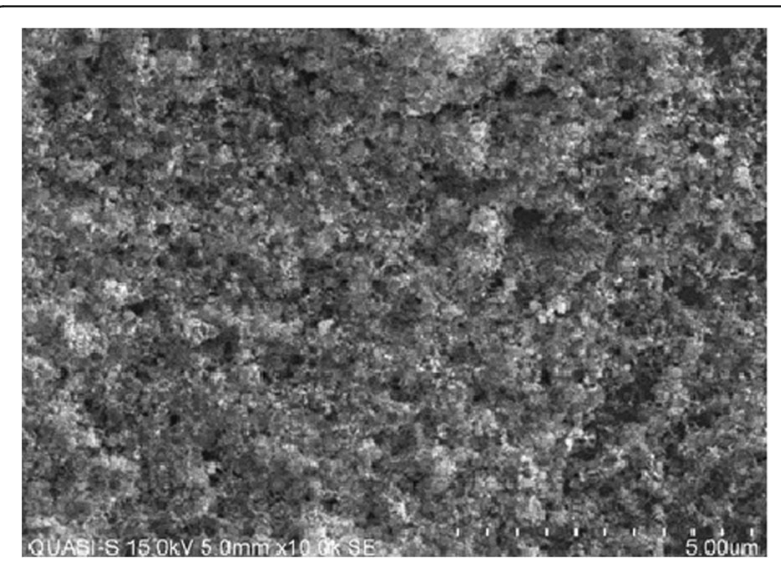

Fig. 4 SEM image for the drop casting the mixture of the Pd-Au 


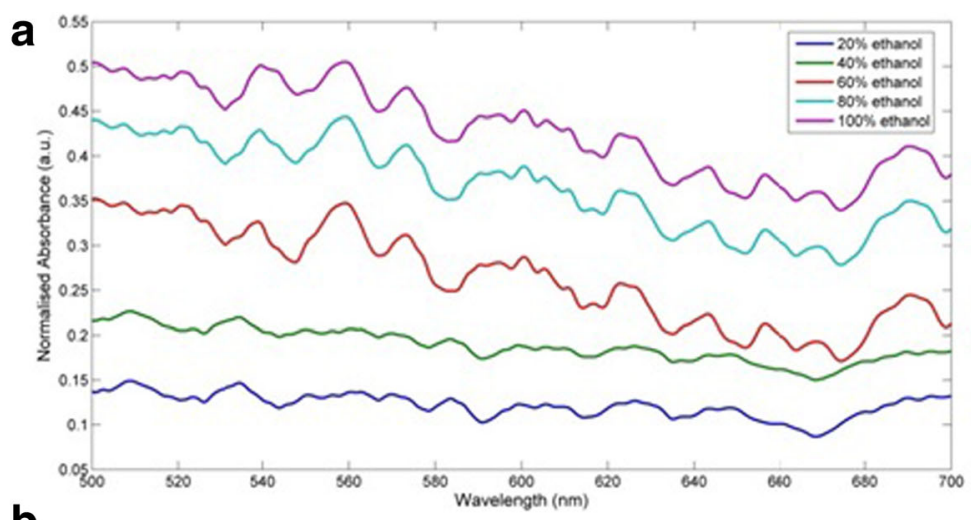

b

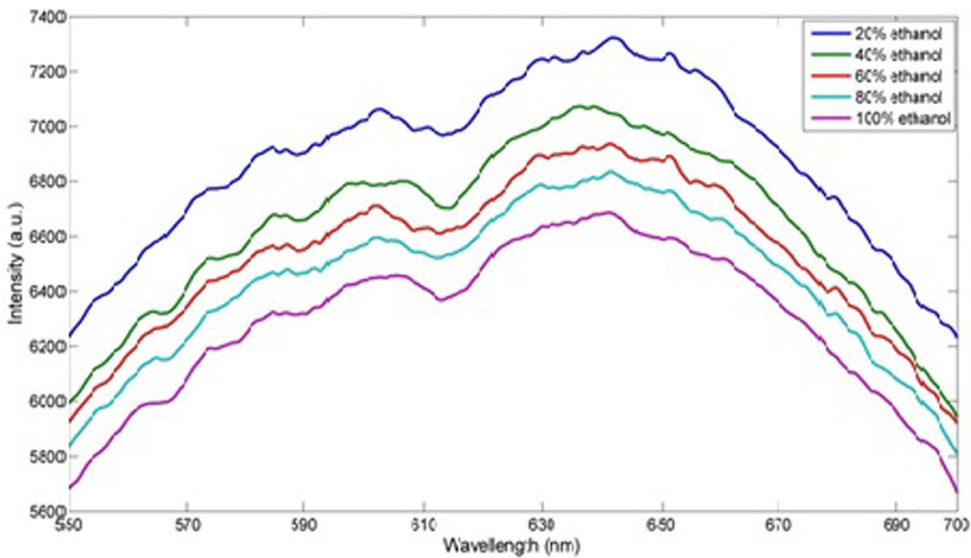

C

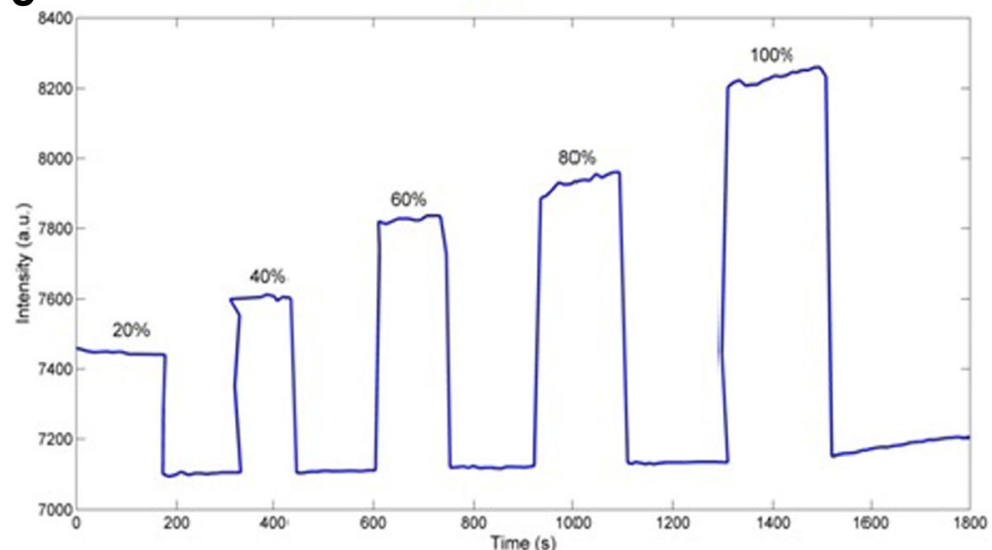

Fig. 5 a Absorbance spectrum of tapered fiber sensor towards Ethanol concentrations, (b) Intensity spectrum of tapered fiber sensor towards Ethanol concentrations, (c) Dynamic response of $2.0 \mathrm{mg} / \mathrm{mol}$ Au coated tapered fiber

The sensor's dynamic response is obtained by integrating the absorbance levels of the sensor from 600 to $700 \mathrm{~nm}$ for each concentration of ethanol. This is performed using the time response feature of the spectrasuite software. First $20 \mathrm{ml}$ of Ethanol solution is inserted into the chamber using syringe. Once the response stabilized, the Ethanol is removed using syringe again. The sensor is allowed to recover to a stable base line. Following the recovery of the sensor, the next concentration of the Ethanol is inserted. These steps are repeated until all the concentrations are completed.

The dynamic response of the sensor was recorded at the wavelength range from $600 \mathrm{~nm}$ to $700 \mathrm{~nm}$ at room temperature. This wavelength was chosen because the sensor exhibited the best response at this region. An average of $18 \mathrm{~s}$ was the time taken by the sensor to respond towards Ethanol and $9 \mathrm{~s}$ was the approximated time taken for the sensor to recover to a stable baseline 

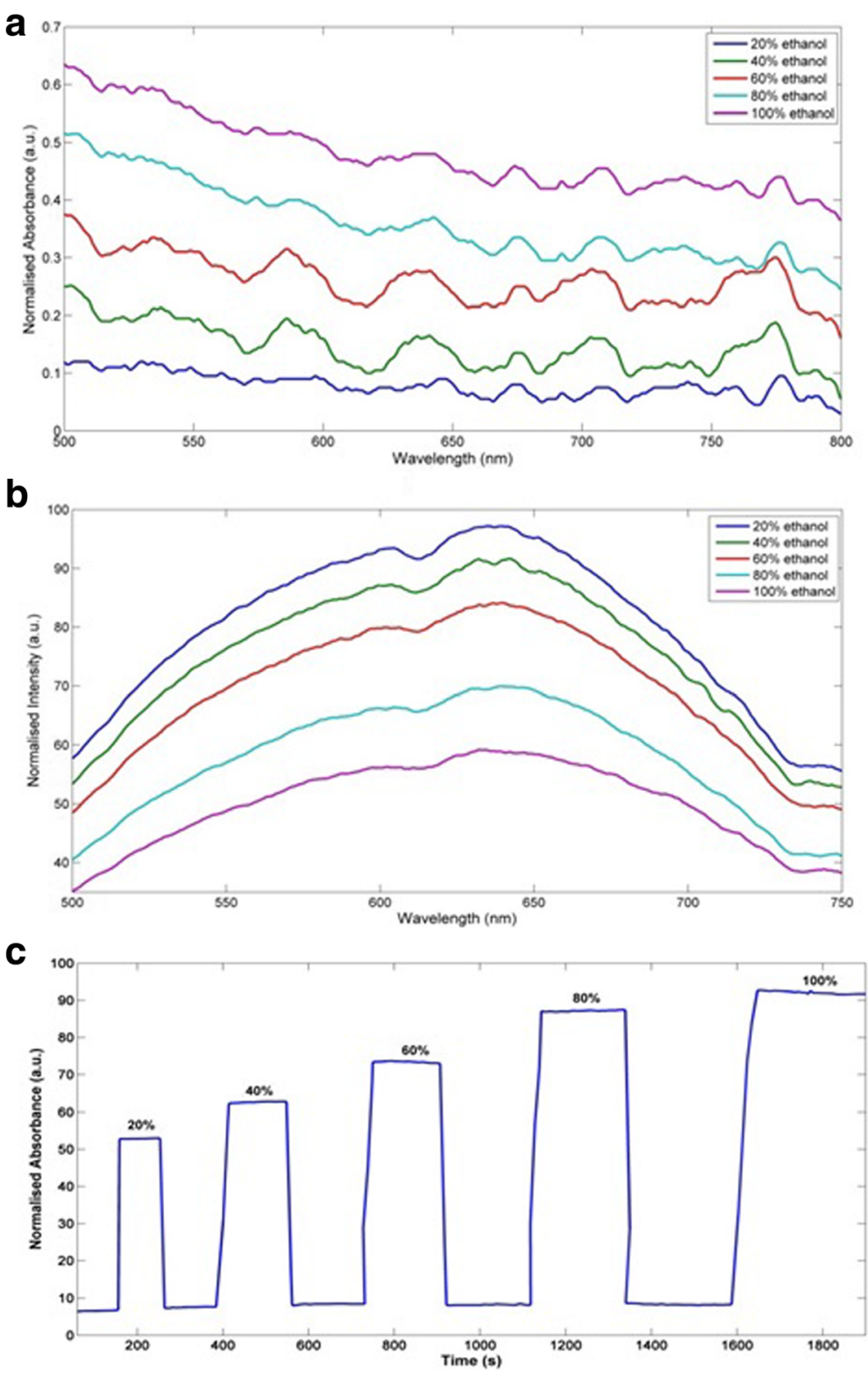

Fig. 6 a Absorbance spectrum of coating fiber sensor with $1.0 \mathrm{mg} / \mathrm{mol}$ palladium towards Ethanol concentrations, (b) Intensity spectrum of tapered fiber sensor towards Ethanol concentrations, (c) Dynamic response of Pd coated MMF sensor towards different concentration of Ethanol

when Ethanol is removed. The dynamic response of the Au coated tapered MMF fiber optic is shown in Fig. 5c.

Next, the response of the palladium coated fiber sensor was investigated. The resultant absorbance and intensity spectrums are shown in Fig. $6 \mathrm{a}$ and $\mathrm{b}$ respectively. As shown in Fig. 6a, the absorbance levels increase as the sensor is exposed to increasing Ethanol concentrations. There is a strong correlation between the ethanol concentrations and the absorbance levels.

A corresponding decrease is intensity levels can be observed in the intensity spectrums as expected. The dynamic response of the $40 \mu \mathrm{m}$ diameter MMF coated with Pd is shown in Fig. 6c. The sensor shows fast response and recovery time of approximately 17 and $12 \mathrm{~s}$ respectively for all of the five concentrations of Ethanol.

The absorbance, intensity and sensor response time of the MMF fiber optic sensor with gold and palladium nanocomposite with ratio of 2: 0.7 (Au to Pd) are shown in Fig. 7a-c below while Fig. $7 \mathrm{~d}$-f show the result obtained from the fourth sensor, coated with gold and palladium nanocomposite with ratio 2: 1 ( $\mathrm{Au}$ to $\mathrm{Pd}$ ). As observed in Fig. 7a-f, the responses of the sensors strongly correspond to the ethanol concentrations. The dynamic responses of the sensors also show fast 

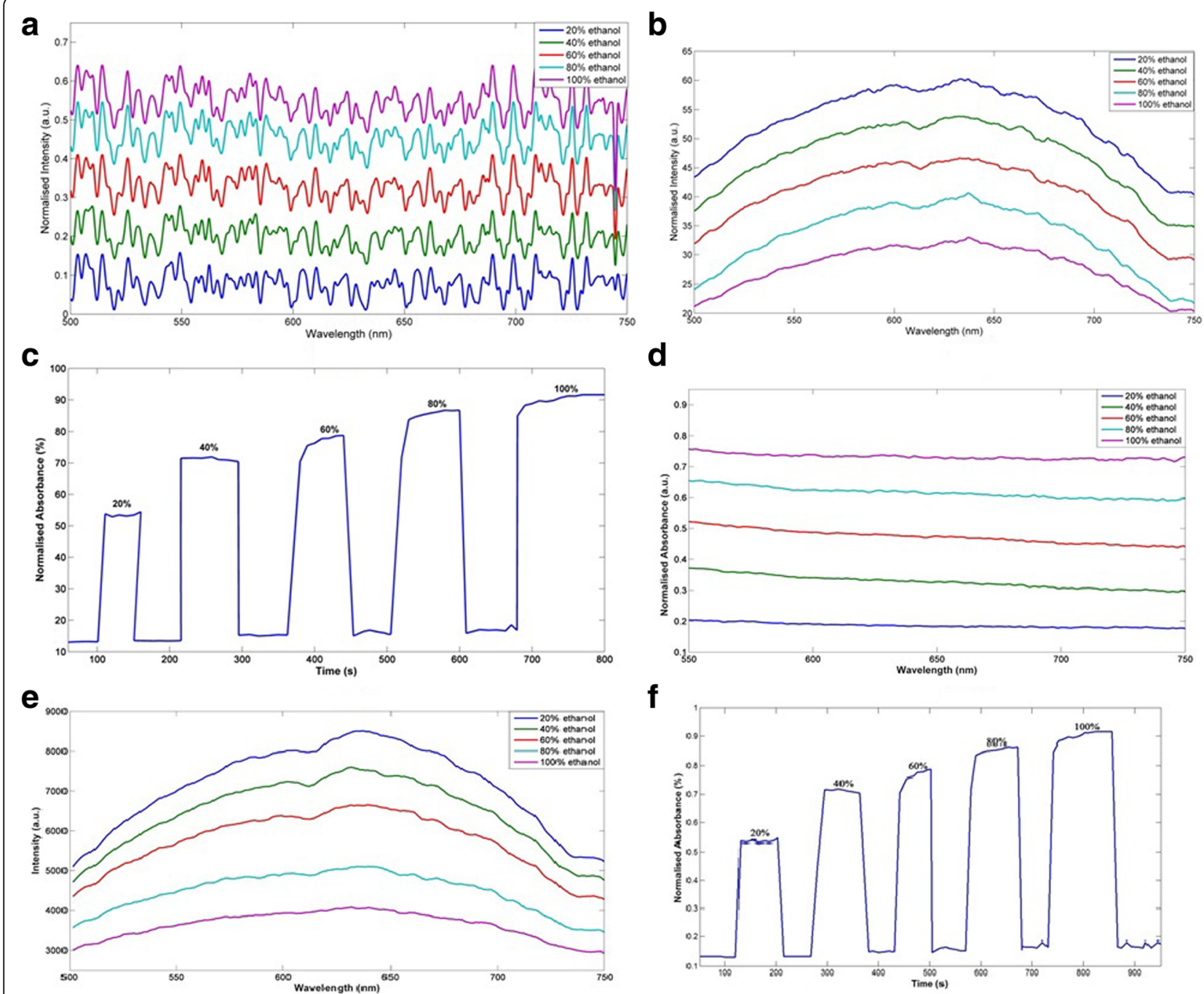

Fig. 7 a Absorbance spectrum of coating fiber sensor with $70 / \mathrm{mol}$ Pd mixture with Au towards Ethanol concentrations. b Intensity spectrum of tapered fiber sensor towards Ethanol concentrations. c Dynamic response. d Absorbance spectrum of coating fiber sensor with $100 / \mathrm{mol} \mathrm{Pd}$ mixture with 200/ mol Au towards Ethanol concentrations. e Intensity spectrum of tapered fiber sensor towards Ethanol concentrations. $\mathbf{f}$ Dynamic response

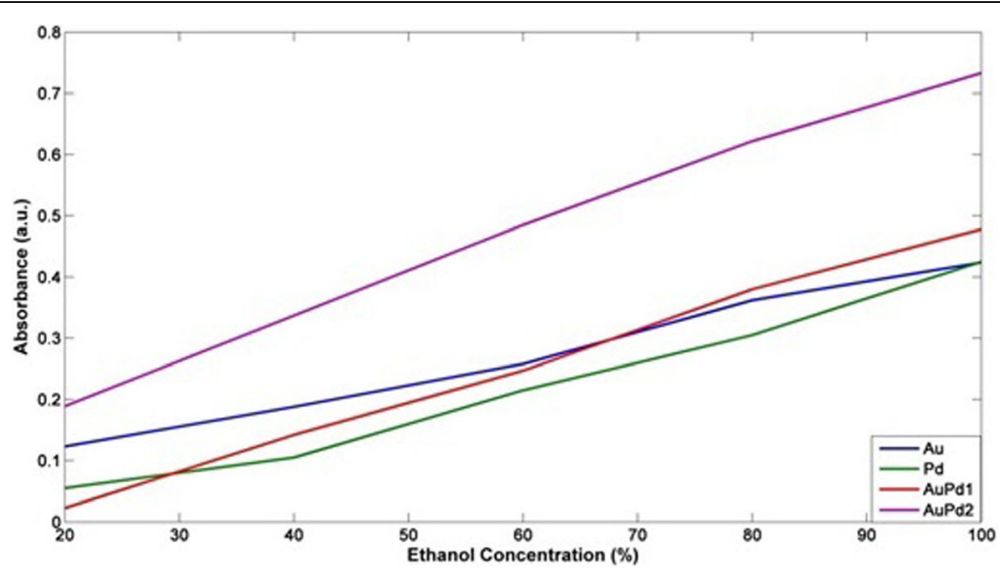

Fig. 8 Comparison of absorbance values towards Ethanol concentrations for developed sensors 
response and recovery and demonstrate stable response as they recover to a steady baseline each time the sample is removed from the liquid chamber.

Figure 8 plots the the absorbance levels against Ethanol concentrations for each of the four sensors in this research. It can be observed that all the sensors show a linear relationship between the absorbance values and the concentration of ethanol.

These results are due to the properties of gold and palladium when they are exposed to Ethanol. Generally, the optical properties of metallic complexes change when VOCs are present. These changes normally happen in refractive index and color. In return, these changes cause a corresponding change to the absorbance spectrum of the tapered fiber sensor. This is similar with the other reported work on fiber optic based Ethanol sensors [20, 26].

The performances of all four sensors are summarized in Table 2. The response and recovery time of the sensors and the sensitivity are compared. The sensitivity is calculated using eq. 1.

$$
S \boldsymbol{n}=\frac{\Delta \% A}{\Delta \% C}
$$

Where: $S n=$ sensitivity, $\mathrm{A}=$ absorbance and $\mathrm{C}=$ concentration.

All the four sensors developed in this research show strong responses towards Ethanol concentrations. The response and recovery time for all 4 sensors are below $20 \mathrm{~s}$. The fastest response is observed with the sensor coated with a gold palladium ratio of 2 to 1 , which are $13 \mathrm{~s}$ for response and $6 \mathrm{~s}$ for recovery. This sensor also demonstrated the highest sensitivity towards ethanol concentrations which is $0.074 / \mathrm{vol} \%$.

This due to the fact that the $\mathrm{Au}, \mathrm{Pd}$ combination causes a unique interaction between the light signal to the sensor surface. The gold nanoparticle enhanced the optical signal in the fiber causing a strong evanescent wave to be present to the surface of the sensor. This will allow the sensor interaction between the light and the surrounding media. The palladium nanoparticles show a strong affinity towards ethanol

Table 2 Performance comparison of developed sensors

\begin{tabular}{llll}
\hline Fibre optic coating & \multicolumn{2}{l}{ Time response } & \multirow{2}{*}{$\begin{array}{l}\text { Sensitivity } \\
\text { vol\% }\end{array}$} \\
\cline { 2 - 3 } & Response time & Recovery time & \\
\hline No coating & $20 \mathrm{~s}$ & $18 \mathrm{~s}$ & $0.003 /$ vol\% \\
Palladium & $17 \mathrm{~s}$ & $12 \mathrm{~s}$ & $0.043 /$ vol\% \\
Gold & $19 \mathrm{~s}$ & $9 \mathrm{~s}$ & $0.005 /$ vol\% \\
Gold: Palladium 2:0.7 & $15 \mathrm{~s}$ & $11 \mathrm{~s}$ & $0.062 /$ vol\% \\
Gold: Palladium 2:1 & $13 \mathrm{~s}$ & $6 \mathrm{~s}$ & $0.074 /$ vol\% \\
\hline
\end{tabular}

molecules [26]. Therefore, the combination of the gold and palladium gives a strong response toward Ethanol detection.

\section{Conclusions}

A tapered multimode fiber sensor coated with gold, palladium and gold palladium nanocomposite with ratios 1:1 and 2:1 has been successfully developed to detect ethanol concentration in water. The sensor was interrogated in the visible region using a broadband white light source and a spectrometer to detect the output. The developed sensors demonstrated high sensitivity towards ethanol concentrations, with the best results obtained from the sensor with the gold palladium coating with a $2: 1$ ratio, where a sensitivity of $0.074 / \mathrm{vol} \%$ is reported. This sensor also gave the fastest dynamic response towards ethanol. This study presents improvement to the sensitivity of fiber optic based ethanol sensor using a larger taper waist diameter. This will contribute towards tapered fiber optic sensors that are more robust and easier to handle.

\section{Funding}

The work reported in this paper has partly supported by the Universiti Putra Malaysia's Research University Grant Schemes (RUGS) (Ref: 05-01-12-1626RU and 05-02-12-2015RU) and Ministry of Higher Education, Malaysia's Fundamental Research Grant Scheme (FRGS) (Ref: 03-04-10-795FR). Both RUGS were used to partly fund the student scholarship throughout his study, whereas FRGS were used to buy all the components and consumable items used in the experiments.

\section{Authors' contributions}

AT: Sensing experiments and Material characterization. MR: Materia Characterization. PT, NT and AM: Data analysis. All authors read and approved the final manuscript.

Competing interests

The authors declare that they have no competing interests.

\section{Publisher's Note}

Springer Nature remains neutral with regard to jurisdictional claims in published maps and institutional affiliations.

\section{Author details}

${ }^{1}$ Wireless and Photonics Network Research Centre of Excellence, Faculty of Engineering, Universiti Putra Malaysia, 43400 UPM Serdang, Selangor, Malaysia. ${ }^{2}$ Department of Computer and Communication Systems Engineering, Faculty of Engineering, Universiti Putra Malaysia, 43400 UPM Serdang, Selangor, Malaysia. ${ }^{3}$ Communication Technology Section, Universiti Kuala Lumpur-British Malaysia Institute, 53100 GOMBAK, Kuala Lumpur, Malaysia. ${ }^{4}$ Department of Physics, Faculty of Science, University Putra Malaysia, 43400 UPM Serdang, Selangor, Malaysia

Received: 30 May 2017 Accepted: 5 October 2017

Published online: 16 October 2017

\section{References}

1. Roh, S., Chung, T., Lee, B.: Overview of the characteristics of microand nano-structured surface plasmon resonance sensors. Sensors. 11(2), 1565-1588 (2011)

2. Homola, J., Yee, S.S., Gauglitz, G.: Surface plasmon resonance sensors: review. Sensors Actuators B Chem. 54(1-2), 3-15 (1999) 
3. Verma, R., Gupta, B.D.: Detection of heavy metal ions in contaminated water by surface plasmon resonance based optical fibre sensor using conducting polymer and chitosan. Food Chem. 166, 568-575 (2015)

4. Sivacoumar, R., Vinoth, M., Alex, Z.C.: Tapered optical fiber bio-sensor for testosterone detection. In: The 14th International Meeting on Chemical Sensors, pp. 821-825 (2012)

5. Hendi, A.A., Alorainy, R.H.: New fabrication of zinc oxide nanostructure thin film gas sensors. Superlattice. Microst. 66, 23-32 (2014)

6. Pandya, H.J., Chandra, S., Vyas, A.L.: Integration of $\mathrm{ZnO}$ nanostructures with MEMS for ethanol sensor. Sensors Actuators B Chem. 161(1), 923-928 (2012)

7. Wang, X.-D., Wolfbeis, O.S.: Fiber-optic chemical sensors and biosensors (2008-2012). Anal. Chem. 85(2), 487-508 (2013)

8. Chen, Y., Li, X., Li, X., Wang, J., Tang, Z.: Sensors and actuators B : chemical UV activated hollow ZnO microspheres for selective ethanol sensors at low temperatures. Sensors Actuators B Chem. 232, 158-164 (2016)

9. Lim, W.H., Yap, Y.K., Chong, W.Y., Ahmad, H.: All-optical Graphene oxide humidity sensors. Sensors (Basel). 14(12), 24329-24337 (2014)

10. Corres, J.M., Arregui, FJ., Matías, I.R.: Sensitivity optimization of tapered optical fiber humidity sensors by means of tuning the thickness of nanostructured sensitive coatings. Sensors Actuators B Chem. 122(2), 442-449 (2007)

11. An, J., Liu, T., Jin, Y.: Fiber optic vibration sensor based on the tilted fiber Bragg grating. Adv. Mater. Sci. Eng. 2013, 1-4 (2013)

12. Sun, Q., Liu, D., Wang, J., Liu, H.: Distributed fiber-optic vibration sensor using a ring mach-Zehnder interferometer. Opt. Commun. 281(6), 1538-1544 (2008)

13. Shabaneh, A.A., Girei, S.H., Arasu, P.T., Rahman, W.B., Bakar, A.A., Sadek, A.Z., Lim, H.N., Huang, N.M., Yaacob, M.H.: Reflectance response of tapered optical fiber coated with graphene oxide nanostructured thin film for aqueous ethanol sensing. Opt. Commun. 331, 320-324 (2014)

14. Aziz, A., Lim, H.N., Girei, S.H., Yaacob, M.H., Mahdi, M.A., Huang, N.M., Pandikumar, A.: Chemical silver / graphene nanocomposite-modified optical fiber sensor platform for ethanol detection in water medium. Sensors Actuators B Chem. 206, 119-125 (2015)

15. Rosli, M.A.A., Arasu, P.T., Noor, A.S.M., Lim, H.N., Huang, N.M.: Reduced Graphene oxide nano-composites layer on fiber optic tip sensor reflectance response for sensing of aqueous ethanol. J. Eur. Opt. Soc. Publ. 12(1), 1 (2016)

16. Lokman, A., Arof, H., Harun, S.W.: Tapered fiber coated with hydroxyethyl cellulose/polyvinylidene fluoride composite for relative humidity sensor. Sensors Actuators A Phys. 225, 128-132 (2015)

17. Bora, T., Fallah, H., Chaudhari, M., Apiwattanadej, T., Harun, S.W., Mohammed, W.S., Dutta, J.: Controlled side coupling of light to cladding mode of $\mathrm{ZnO}$ nanorod coated optical fibers and its implications for chemical vapor sensing. Sensors Actuators B Chem. 202, 543-550 (2014)

18. Girei, S.H., Shabaneh, A.A., Arasu, P.T., Yaacob, M.H.: Tapered multimode fiber sensor for ethanol sensing application. In: International Conference on Photonics, vol. 2, pp. 2-4 (2014)

19. Zhang, C., Lin, N., Chai, X., Barnes, D.G.: A rapid method for simultaneously determining ethanol and methanol content in wines by full evaporation headspace gas chromatography. Food Chem. 183, 169-172 (2015)

20. Arasu, P., Noor, A.S.M., Shabaneh, A.A.: Absorbance properties of gold coated fiber Bragg grating sensor for aqueous ethanol. J. Eur. Opt. Soc. 9, 14018 (2014)

21. Shaws Infrastructure and Environmental Group, "Large Volume Ethanol SpillsEnvironmental Impacts and Response Options," MassDEP, no. July, 2011

22. Periasamy, A.P., Umasankar, Y., Chen, S.M.: Toluidine blue adsorbed on alcohol dehydrogenase modified glassy carbon electrode for voltammetric determination of ethanol. Talanta. 83(3), 930-936 (2011)

23. Mirzaei, A., Janghorban, K., Hashemi, B., Bonyani, M., Leonardi, S.G., Neri, G. Highly stable and selective ethanol sensor based on a -Fe 203 nanoparticles prepared by Pechini sol - gel method. Ceram. Int. 42(5), 6136-6144 (2016)

24. Arasu, P.T., Noor, A.S.M., Shabaneh, A.A., Yaacob, M.H., Lim, H.N., Mahdi, M.A.: Fiber Bragg grating assisted surface plasmon resonance sensor with graphene oxide sensing layer. Opt. Commun. 380, 260-266 (2016)

25. Rosli, M.A.A., Arasu, P.T., Lim, H.N., Noor, A.S.M.: Dynamic response of tapered optical fiber coated with Graphene oxide for detecting aqueous ethanol. In: IEEE 6th International Conference on Photonics, pp. 16-18 (2016)

26. Liewhiran, C., Phanichphant, S.: Effects of palladium loading on the response of thick film flame-made $\mathrm{ZnO}$ gas sensor for detection of ethanol vapor. Sensors. 7(7), 1159-1184 (2007)

\section{Submit your manuscript to a SpringerOpen ${ }^{\circ}$ journal and benefit from:}

- Convenient online submission

- Rigorous peer review

- Open access: articles freely available online

- High visibility within the field

- Retaining the copyright to your article

Submit your next manuscript at $\gg$ springeropen.com 